\title{
'Candidatus Liberibacter asiaticus' Titers in Citrus and Acquisition Rates by Diaphorina citri Are Decreased by Higher Temperature
}

\author{
S. A. Lopes, F. Q. B. F. Luiz, E. C. Martins, C. G. Fassini, and M. C. Sousa, Fundecitrus, Araraquara; J. C. Barbosa, UNESP, \\ Jaboticabal, SP, Brazil; and G. A. C. Beattie, University of Western Sydney, Penrith South DC, NSW, Australia
}

\begin{abstract}
Lopes, S. A., Luiz, F. Q. B. F., Martins, E. C., Fassini, C. G., Sousa, M. C., Barbosa, J. C., and Beattie, G. A. C. 2013. 'Candidatus Liberibacter asiaticus' titers in citrus and acquisition rates by Diaphorina citri are decreased by higher temperature. Plant Dis. 97:1563-1570.

'Candidatus Liberibacter asiaticus' is the most prevalent Liberibacter sp. associated with huanglongbing (HLB) in Brazil. Within São Paulo state (SP), HLB has spread more rapidly to and reached higher incidence in regions with relatively mild (cooler) summer temperatures. This suggests that climate can influence disease spread and severity. ' $\mathrm{Ca}$. L. asiaticus' titers on soft, immature leaves from infected 'Valencia' sweet orange plants exposed to different temperature regimes and adult Diaphorina citri fed for $48 \mathrm{~h}$ on these plants for ' $\mathrm{Ca}$. L. asiaticus' acquisition were determined by quantitative polymerase chain reaction in two experiments. The first experiment included plants with three levels of infection, three incubation periods (IPs), and air temperatures

favorable $\left(14.6\right.$ to $\left.28^{\circ} \mathrm{C}\right)$ and unfavorable $\left(24\right.$ to $\left.38^{\circ} \mathrm{C}\right)$ to ' $\mathrm{Ca}$. $\mathrm{L}$. asiaticus'. The second included plants with severe late-stage infections, 10 IPs (based on 3-day intervals over 27 days), and three air temperature regimes ( 12 to 24,18 to 30 , and 24 to $38^{\circ} \mathrm{C}$ ). Overall, ' $\mathrm{Ca}$. L. asiaticus' titers and the percentages of ' $\mathrm{Ca}$. L. asiaticus'-positive psyllids were lower in plants maintained at the warmer temperature regime (24 to $38^{\circ} \mathrm{C}$ ) than in plants maintained in the cooler regimes. The results suggest that the lower incidence and slower spread of ' $\mathrm{Ca}$. L. asiaticus' to warmer regions of SP are related to the influence of ambient temperatures on titers of ' $\mathrm{Ca}$. L. asiaticus' in leaves.
\end{abstract}

Huanglongbing (HLB) is the most destructive citrus disease $(2,5,7)$. In Brazil, it is associated with two phloem-limited bacteria, 'Candidatus Liberibacter asiaticus' and ' $C a$. L. americanus' $(4,22)$, $\alpha$-proteobacteria that are transmitted by the Asian citrus psyllid, Diaphorina citri Kuwayama $(3,25)$. Both pathogens have been detected in all commercial citrus cultivars and, to a markedly less extent and distribution, in the common ornamental orange jasmine Murraya exotica L. (15).

HLB was initially found in Brazil in 2004, in two municipalities of São Paulo state. It has since spread rapidly, being reported in over 300 municipalities of São Paulo, Paraná, and Minas Gerais states. In São Paulo, incidences of affected blocks and plants have increased from 18.6 and $0.6 \%$ in 2008 (1) to 53.3 and $3.8 \%$ in 2011 (16), and 64.1 and $6.9 \%$ in 2012 . However, spatial progress and the distribution of the disease in the state have not been uniform. Spread has been less rapid and incidence of the disease lower in the relatively warmer northern portions of the state despite the number and distribution of citrus orchards and the presence of D. citri favoring uniform spread of the disease in all directions from the initial detection point (12). Moreover, levels of infection attained by the pathogens have not been uniform. Relative proportions of ' $\mathrm{Ca}$. L. asiaticus' to that of ' $\mathrm{Ca}$. L. americanus' in Liberibacter polymerase chain reaction (PCR) plus samples sent by growers to the Fundecitrus laboratory in Araraquara have changed from 2 versus $98 \%$ in 2004 to $>99$ versus $<1 \%$ in 2012 (12; N. Wulff, unpublished data).

Reasons for the uneven distribution of the disease and for the shift in proportions of infections related to either ' $\mathrm{Ca}$. L. asiaticus' or ' $\mathrm{Ca}$. L. americanus' are not well understood. However, ' $\mathrm{Ca}$. L. asiaticus' titers in field-infected or artificially inoculated plants can be at least 10 times higher than ' $\mathrm{Ca}$. L. americanus' titers, and ' $\mathrm{Ca}$. L. asiaticus' is more efficiently transmitted by grafting and $D$. citri

Corresponding author: S. A. Lopes, E-mail: slopes@fundecitrus.com.br

Accepted for publication 14 May 2013.

http://dx.doi.org/10.1094/PDIS-11-12-1031-RE

(C) 2013 The American Phytopathological Society than ' $C a$. L. americanus' (12; unpublished data). Moreover, in a growth chamber, ' $\mathrm{Ca}$. L. asiaticus' tolerates air temperatures that are detrimental to ' $\mathrm{Ca}$. L. americanus': ' $\mathrm{Ca}$. L. americanus' is partially or totally eliminated from infected citrus trees exposed to daily regimes of maximum air temperatures of $32^{\circ} \mathrm{C}$ and above whereas ' $\mathrm{Ca}$. L. asiaticus' is only partially affected by temperatures of 32 or $38^{\circ} \mathrm{C}(14)$. Nevertheless, air temperatures of $38^{\circ} \mathrm{C}$ caused 1,000 -fold or greater declines in ' $\mathrm{Ca}$. L. asiaticus' titers in mature leaves of infected plants.

Because maximum daily temperatures around $38^{\circ} \mathrm{C}$ are common during the summer in the northern regions of São Paulo (http:// www.ciiagro.sp.gov.br/ciiagroonline/), the local environment may not be favorable for ' $\mathrm{Ca}$. L. asiaticus' survival and multiplication in plant tissues, thereby restricting spread of the disease in the field to a greater extent than would occur in cooler regions. To test this hypothesis, experiments were performed to determine the effect of air temperatures on ' $C a$. L. asiaticus' multiplication in immature flush growth on citrus plants and acquisition of the pathogen from these growth flushes by $D$. citri.

\section{Materials and Methods}

Pathogen-free $D$. citri colonies. Adult D. citri were collected from healthy orange jasmine trees growing in public gardens of Santa Fé do Sul, a municipality located in northwestern São Paulo, in a region still free from HLB. The insects were confined inside screen bags on potted orange jasmine plants. The plants were transported to Fundecitrus in Araraquara and the insects were transferred to approximately 50 - $\mathrm{cm}$-tall healthy orange jasmine and citrus plants maintained in a climate-controlled room at $26 \pm$ $2^{\circ} \mathrm{C}$ or inside a growth chamber (CMP4030; Conviron) programmed for temperature ranges of 24 to $30^{\circ} \mathrm{C}$. The apical branches of the plants used for transport and confinement had been pruned 2 weeks prior to collection of the psyllids to allow time for emergence of new growth suitable for psyllid feeding and oviposition. When eggs were observed, usually 2 to 3 weeks after adult psyllids were transferred to the plants, all fieldcollected adults were removed and the eggs were allowed to hatch to establish new colonies. Combined samples of five adult individuals each taken from the field and the new colonies were processed for DNA extraction and analyzed by quantitative PCR 
(qPCR) for 'Ca. L. americanus' or ' $\mathrm{Ca}$. L. asiaticus' detection (see below).

Experimental designs. Two experiments were carried out involving ' $\mathrm{Ca}$. L. asiaticus'-infected, graft-inoculated, 1.5-year-old potted sweet orange (Citrus sinensis (L.) Osbeck) 'Valencia' plants grown on Rangpur (Citrus $\times$ limonia Osbeck) rootstock and approximately 30 -day-old adult $D$. citri. In the first experiment (Fig. 1), conducted from May to November 2010, the effects of air temperatures on ' $\mathrm{Ca}$. L. asiaticus' titers were assessed on infected plants at varying times after inoculation.

The purpose was to determine whether a daily regime with a maximum air temperature of $38^{\circ} \mathrm{C}$ would similarly affect ' $\mathrm{Ca}$. $\mathrm{L}$. asiaticus' multiplication in plants at early, intermediate, or late stages of infection. A group of 126 healthy plants growing in commercial organic substrate made of fine pine bark in 12-liter plastic bags was graft inoculated on their stems with two 4-cm-long budsticks from ' $\mathrm{Ca}$. L. asiaticus'-positive Valencia orange plants, as described (13). The plants were housed in a greenhouse with a fan and evaporative cooling system set to maintain air temperatures at $\leq 28^{\circ} \mathrm{C}$. At 2,4 , and 6 months post inoculation $(60,120$, and 180 days post inoculation [dpi]), the plants were assessed for the presence of HLB and mineral-deficiency symptoms on the mature leaves, and lopped at the stem approximately $20 \mathrm{~cm}$ above the inoculation site. Immediately after pruning, groups of 25 plants, composed of 21 inoculated and 4 noninoculated controls, were selected and retained in the greenhouse, and a group with the same number of plants was transferred to a growth chamber. During the course of the experiment, the average daily air temperature in the greenhouse varied between 14.6 and $28^{\circ} \mathrm{C}$. The growth chamber was programmed to a daily regime of 24 to $38^{\circ} \mathrm{C}$, distributed as follows: $12 \mathrm{~h}$ at $24^{\circ} \mathrm{C}$ in darkness, $3 \mathrm{~h}$ to increase from 24 to $38^{\circ} \mathrm{C}$ in light, $6 \mathrm{~h}$ at $38^{\circ} \mathrm{C}$ in light, and $3 \mathrm{~h}$ to decrease from 38 to $24^{\circ} \mathrm{C}$ in light, as used previously in other studies (14). Light was provided by $125-$ and $250-\mathrm{W}$ tubular fluorescent and $40-\mathrm{W}$ incandescent lamps. Plants were then exposed to environments in either the greenhouse or growth chamber for 15,30 , or 60 days and then transferred to a climate-controlled room at $26^{\circ} \mathrm{C}\left( \pm 2^{\circ} \mathrm{C}\right)$. Immediately after the plants were transferred to the climate-controlled room, groups of 20 approximately 1-month-old, pathogen-free adult psyllids were confined inside separate 10 - by $20-\mathrm{cm}-\mathrm{long}$ screen bags enclosing the terminal growth flush on the plants, for a ' $C a$. L. asiaticus' acquisition-access period (AAP) of $48 \mathrm{~h}$. The new flushes were composed of young and fully expanded soft leaves, preferable feeding sites of $D$. citri. The insects and the leaves on which they were confined were collected separately and processed for DNA extraction and qPCR analysis. To determine whether viable ' $\mathrm{Ca}$. L. asiaticus' cells were present on the stems of the experimental plants, attempts were made to transmit the pathogen from the experimental to new healthy plants. The upper portion of the mature stem, just below the site where the new shoots had developed, was removed from each experimental plant and, in each instance, side-grafted onto the stem of two healthy 1year-old Valencia plants on Swingle citrumelo ( $C$. paradisi 'Duncan Grapefruit' Macf. × Poncirus trifoliata L. (Raf.)) rootstock, as described (13). To increase the chances of ' $\mathrm{Ca}$. L. asiaticus' transmission, each healthy plant was graft inoculated with two budsticks positioned on opposite side of the stems. The graft-inoculated plants were maintained inside the greenhouse for 1 year and then evaluated on the basis of visual symptoms and qPCR.

The results of the first experiment were analyzed and used as a basis for a second experiment, which was carried out solely within growth chambers. In the second experiment (Fig. 2), the effect of temperature on ' $\mathrm{Ca}$. L. asiaticus' populations was assessed on the new flushes of 150 ' $C a$. L. asiaticus'+, 1.5-year-old Valencia orange plants growing on Rangpur rootstocks in 5-liter bags containing pine bark as substrate. The plants had been maintained in the greenhouse for 1 year after they were inoculated and were expressing severe symptoms of late-stage infections of HLB; namely, mottling and symptoms of zinc and manganese deficiencies on several mature leaves. The plants were lopped approximately $20 \mathrm{~cm}$ above the inoculation site as in the first experiment.

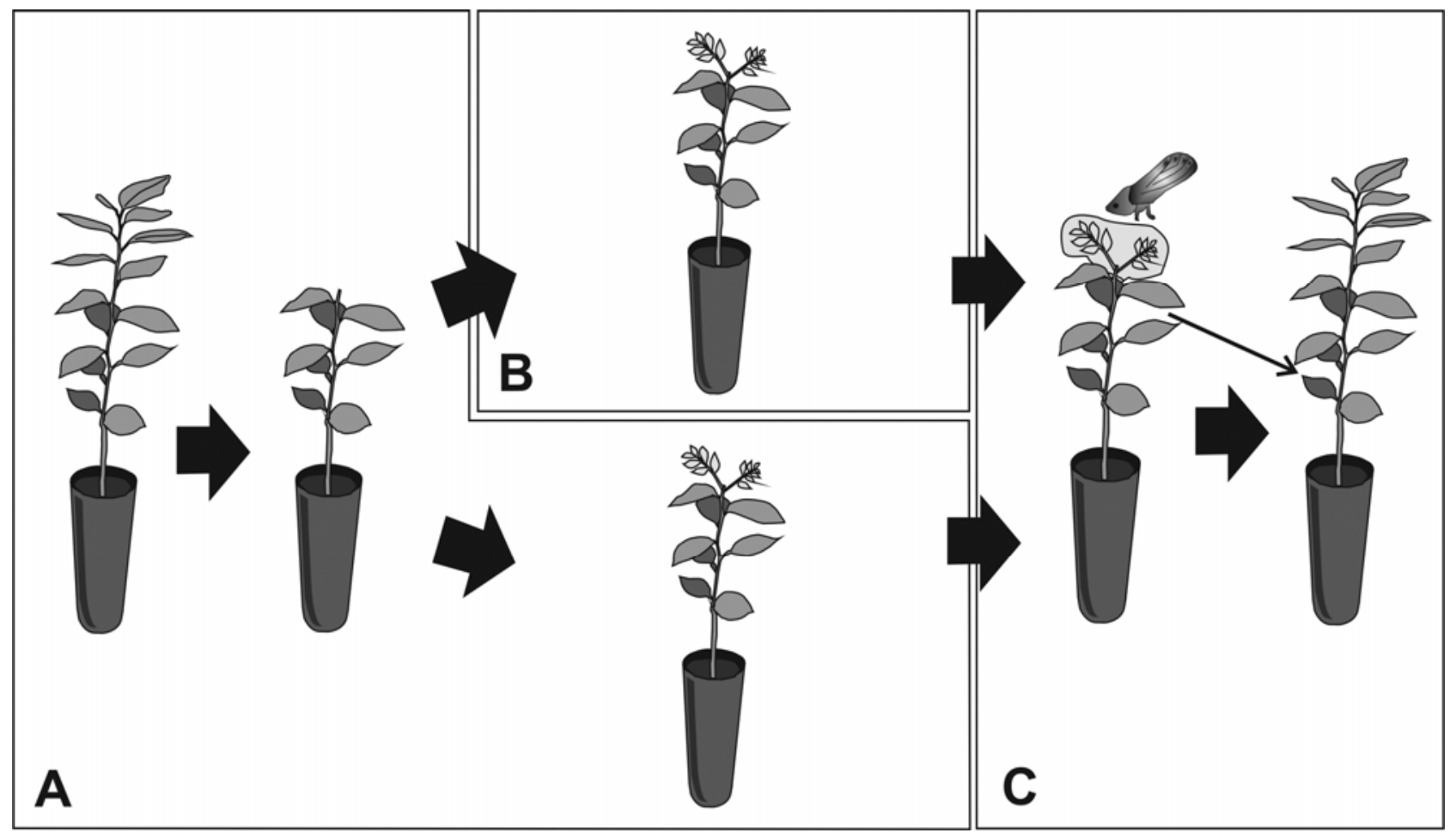

Fig. 1. Schematic representation of the procedures followed in experiment 1. Healthy plants were inoculated, A, maintained in the greenhouse at 14.6 to $28^{\circ} \mathrm{C}$, and pruned after 60,120 , or 180 days. B, Just after pruning, half of the pruned plants were retained in the greenhouse for 15,30 , or 60 days, and half transferred to and retained for identical intervals in a growth chamber at 24 to $38^{\circ} \mathrm{C}$. C, Plants were transferred to a climate-controlled room at $26^{\circ} \mathrm{C}\left( \pm 2^{\circ} \mathrm{C}\right)$, where Diaphorina citri adults were confined on the new growth flushes for $48 \mathrm{~h}$. Insects and flush growths were processed and analyzed by quantitative polymerase chain reaction, and budsticks were used to inoculate healthy new plants in the greenhouse. 
Three weeks after pruning, when the newly developed shoots were 5 to $10 \mathrm{~cm}$ long, the plants were transferred to three identical growth chambers, each programmed with different daily temperature regimes: 24 to $38^{\circ} \mathrm{C}$ (as in the first experiment), 18 to $30^{\circ} \mathrm{C}$, and 12 to $24^{\circ} \mathrm{C}$. The number of hours the plants were exposed to maximum, minimum, increasing, and decreasing temperatures each day, as well as light and darkness, were as described for the 24 to $38^{\circ} \mathrm{C}$ regime in the first experiment. The plants were exposed to the three distinct environmental conditions for intervals of $3,6,9,12,15,18,21,24,27$, or 30 days. At each of these intervals, five plants were removed from each chamber and transferred to the climate-controlled room. As in the first experiment, immediately after the plants were transferred, a group of 20 adult $D$. citri was confined in one growing terminal flush of each plant for a 48-h AAP. The insects and the plant tissues on which they were confined were then removed from each plant and processed separately and individually for qPCR analysis.

The effect of the 24 to $38^{\circ} \mathrm{C}$ regime on ' $\mathrm{Ca}$. L. asiaticus' multiplication and acquisition was further tested on an individual 5-year-old and on a group of 25 1.5-year-old graft-inoculated fully symptomatic (late infections) plants. The individual plant was maintained inside the growth chamber for 9 days. The flushes, in numbers of 8 to 10 , were removed on days $0,1,3,5,7$, and 9 and transferred individually to $50-\mathrm{ml}$ Falcon tubes containing $10 \mathrm{ml}$ of Milli-Q filtered water, in which the basal portion of the new flushes were immersed. Groups of three insects were then confined on each flush for a 48 -h AAP at $26^{\circ} \mathrm{C}$. Flushes and groups of insects were subjected separately to qPCR analysis. The 1.5 -yearold plants were maintained inside the growth chamber for 5 days.
Every $24 \mathrm{~h}$, a group of five plants was removed from the chamber and groups of 10 insects were confined on the new flushes, as indicated in the second experiment. After the 48-h AAP, five individual insects were removed from each plant and subjected individually to $\mathrm{qPCR}$ analysis.

DNA extraction. Plant and psyllid total DNAs were extracted using the cetyltrimethylammonium bromide buffer of Murray and Thompson (17). Each plant sample consisted of $250 \mathrm{mg}$ of leaf midribs and petioles. The tissues were finely chopped and macerated as described (22). D. citri samples consisted of an individual adult insect or lots of three or five adult individuals crushed in liquid nitrogen in 1.5-ml Eppendorf tubes. In each round of psyllid DNA extraction, noninfective individuals were included as controls of the extraction procedure. Plant and psyllid DNAs were eluted in 50 and $30 \mu \mathrm{l}$, respectively, of Milli-Q filtered water and stored at $-20^{\circ} \mathrm{C}$ until use.

' $\boldsymbol{C a}$. L. asiaticus' DNA quantification. A standard curve was prepared using amplified PCR product of the gene $16 \mathrm{~S}$ ribosomal RNA (rRNA) of ' $C a$. L. asiaticus' (11), as described (6). The 1,160-bp product was amplified from total DNA of a ' $\mathrm{Ca}$. L. asiaticus'-infected citrus plant through conventional PCR using the primers Oi1 and Oi2C (8), purified with the PCR Clean-Up System (Promega Corp.), and quantified using the Nanodrop UV densitometry (Thermo Scientific, Nanodrop Products). Mass conversion of ds16S rRNA to molecule copy number was performed (12). Tenfold serial dilutions were then prepared from $2.36 \times 10^{8}$ to $2.36 \times 10^{1}$ molecules in a solution containing total genomic DNA at $100 \mathrm{ng} / \mu \mathrm{l}$ extracted from healthy citrus leaves (for quantification of 'Ca. L. asiaticus' genomes in plant samples),

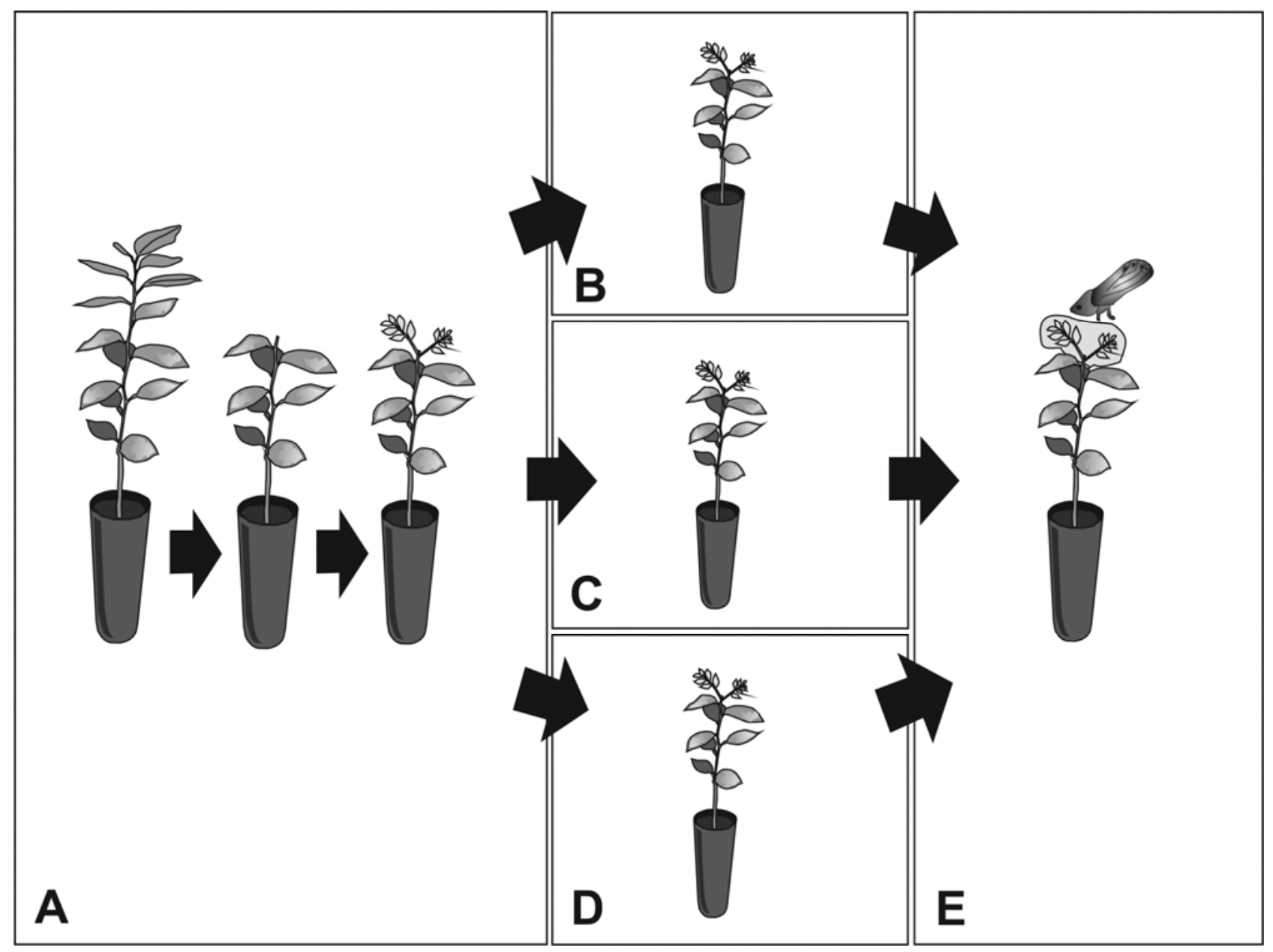

Fig. 2. A, Fully symptomatic plants were pruned, maintained in the greenhouse for 3 weeks, and transferred to and maintained for 30 days at $\mathrm{B}, 18$ to $30^{\circ} \mathrm{C} ; \mathrm{C}, 12$ to $24^{\circ} \mathrm{C}$; and D, 24 to $38^{\circ} \mathrm{C}$ inside three identical growth chambers. E, Plants were removed from each chamber at 3-day intervals and transferred to the climate-controlled room, where adults of Diaphorina citri were confined onto the growth flushes as in the first experiment. Insects and flush growths were processed and analyzed by quantitative polymerase chain reaction. 
or in solution containing total genomic DNA at $100 \mathrm{ng} / \mu \mathrm{l}$ extracted from noninfective adult psyllids (for quantification of ' $\mathrm{Ca}$. $\mathrm{L}$. asiaticus' genomes in $D$. citri samples). The dilutions were processed in genomic DNAs of healthy plants (11) or insects to minimize any potential effect that the DNA of these organisms, which was present in all samples to be analyzed, could have on the amplification efficiency of the target DNA. The dilutions were employed in triplicate to generate separate standard curves for ' $\mathrm{Ca}$. L. asiaticus' genome quantifications in plants or insects. The number of ' $C a$. L. asiaticus' genomes present in each gram of plant DNA sample or in each sample of adult $D$. citri was determined considering that each bacterium cell contains three copies of the target 16S rRNA gene (10).

Real-time PCR conditions. All qPCR reactions were performed in a StepOne Plus thermocycler (Applied Biosystems) using the TaqMan system and the described primer set for ' $C a$. L. asiaticus' or ' $\mathrm{Ca}$. L. americanus' quantification (11), after a few modifications. The reaction solution contained $500 \mathrm{nM}$ each of the primers HLBas and HLBr or HLBam and HLBr for ' $\mathrm{Ca}$. L. asiaticus' and 'Ca. L. americanus' detections, respectively, and $200 \mathrm{nM}$ probe HLBp and $1 \times$ Path ID master mix (Applied Biosystems). For detection and quantification of ' $\mathrm{Ca}$. L. asiaticus', qPCR was run in a total volume of $12 \mu \mathrm{l}$ containing $9 \mu \mathrm{l}$ of reaction solution plus 3 $\mu \mathrm{l}$ of plant DNA samples, previously adjusted to a concentration of $100 \mathrm{ng} / \mu \mathrm{l}$, or $3 \mu \mathrm{l}$ of undiluted psyllid DNA samples. Cycling parameters were $95^{\circ} \mathrm{C}$ for $20 \mathrm{~s}$ followed by 45 cycles of $95^{\circ} \mathrm{C}$ for 3 $\mathrm{s}$ and $60^{\circ} \mathrm{C}$ for $30 \mathrm{~s}$. To detect any potential sample contamination, each plate contained in duplicate negative and positive controls, which consisted of DNA extracted from healthy or ' $\mathrm{Ca}$. L. asiaticus'-infected citrus, respectively, or DNAs extracted from noninfective or ' $C a$. L. asiaticus'-carrying adult psyllids, respectively. Due to the large number of samples being analyzed, to identify any potential plate-to-plate variation in quantification cycle $(\mathrm{Cq})$ values, besides using the same positive and negative controls in all plates, the plates also contained approximately the same number of samples of each experimental treatment. Each sample was run in duplicate, with the average titers of ' $\mathrm{Ca}$. L. asiaticus' genomes used in the statistical analysis. Samples that resulted in "undetermined" or in Cq values above 34.00 were further analyzed by qPCR by adding to the master mix, as internal controls, the probe primer sets targeting the citrus cytochrome oxidase (Cox) or the insect wingless $(\mathrm{Wg})$ gene regions $(11,23)$.

Data analysis. Statistical analysis was performed on the logarithm of the number of ' $\mathrm{Ca}$. L. asiaticus' genome copies per gram of plant tissue or individual psyllid sample. The analyses were performed only on samples testing positive for the presence of ' $C a$. L. asiaticus'. Log values were subjected to analysis of variance followed by the Tukey test for mean comparisons. All analyses were performed using SAS software (20).

\section{Results}

New $D$. citri colonies. The temperature range of 24 to $30^{\circ} \mathrm{C}$ was adequate for the establishment of new colonies of $D$. citri. Large numbers of eggs were observed 2 to 3 weeks after the transfer of the field insects to the new plants, and substantial numbers of adults ecloded after 3 weeks. Fewer insects were produced on citrus than on orange jasmine plants kept in the same environment. qPCR analysis of the field-collected and resulting colonies tested negative for either ' $\mathrm{Ca}$. L. asiaticus' or ' $\mathrm{Ca}$. L. americanus'.

' $\mathrm{Ca}$. L. asiaticus' quantifications in plants and psyllids. ' $\mathrm{Ca}$. L. asiaticus' quantifications from plant or psyllid samples were done separately, using the derived standard curves involving the $\mathrm{Cq}$ values and the logarithm of the $16 \mathrm{~S}$ rRNA copies for ' $\mathrm{Ca}$. L. asiaticus' (Fig. 3). Linear relationships were detected among $\mathrm{Cq}$ and the $\log$ 16S rRNA for ' $C a$. L. asiaticus' quantification in plants $(y=$ $\left.-0.2998 \mathrm{Cq}+11.042, R^{2}=0.9981\right)$ (Fig. 3A) or psyllids $(y=$ $\left.-0.2904 \mathrm{Cq}+11.085, R^{2}=0.9996\right)($ Fig. 3B). Target gene concentrations lower than $0.9 \log 16 \mathrm{~S}$ rDNA in plant or $1.2 \mathrm{log}$ in psyllid samples, which corresponded to a $\mathrm{Cq}$ value of 34.00 , produced variable results. Therefore, the $\mathrm{Cq}$ value of 34.0 was used as the lower detection limit for ' $C a$. L. asiaticus' quantification in both plants and psyllids. The primer probe set for Cox and $\mathrm{Wg}$ genes used in the master mix as internal controls indicated that all ' $\mathrm{Ca}$. L. asiaticus'-positive and -negative samples contained adequate amounts of citrus or $D$. citri DNAs for qPCR amplifications. The $\mathrm{Cq}$ values for Cox internal control averaged $16.42( \pm 0.18)$ in ' $\mathrm{Ca}$. L. asiaticus'-positive and $16.59( \pm 0.10)$ in ' $C a$. L. asiaticus'-negative citrus samples. The $\mathrm{Cq}$ values for $\mathrm{Wg}$ internal control averaged $24.14( \pm 0.15)$ in 'Ca. L. asiaticus'-positive and $24.42( \pm 0.16)$ in 'Ca. L. asiaticus'-negative $D$. citri samples.

First experiment. When plants were pruned and transferred to the growth chamber or maintained in the greenhouse, none of the plants from the first group (60 dpi) exhibited HLB symptoms on mature leaves but mature leaves on plants of the second group (120 dpi) exhibited general light chlorosis. The intensity of yellowing was more intense on plants of the third group (180 dpi), and these plants also exhibited typical HLB mottling and mineral-deficiency symptoms similar to those induced by lack of zinc or manganese. New flush growth developed on all pruned plants in the greenhouse and growth chamber. Adults of D. citri were then caged on the upper portions of the new growth, which consisted of fully expanded immature leaves, for $48 \mathrm{~h}$ for ' $\mathrm{Ca}$. L. asiaticus' acquisition. After the acquisition period, plant tissues and the insects were processed for qPCR analyses.

A lower average percentage of ' $\mathrm{Ca}$. L. asiaticus'-positive flushes (Table 1) occurred on the 60-dpi plants maintained inside the growth chamber $(14.3 \%)$ than on those maintained in the greenhouse $(90.5 \%)$ after all three incubation periods. ' $\mathrm{Ca}$. L. asiaticus' was detected in $95.2 \%$ of the flushes on the 120-dpi plants in both environments and in 76.9 and $93.3 \%$ of the flushes on the 180-dpi plants maintained in the greenhouse and growth chamber, respectively, after all three incubation periods.

The growth chamber temperatures seemed to affect the ability of ' $C a$. L. asiaticus' to multiply in plant tissues. Although mean differences were statistically significant $(P<0.01)$ only for the first two incubation periods (15 and 30 days) on the 60-dpi plants,
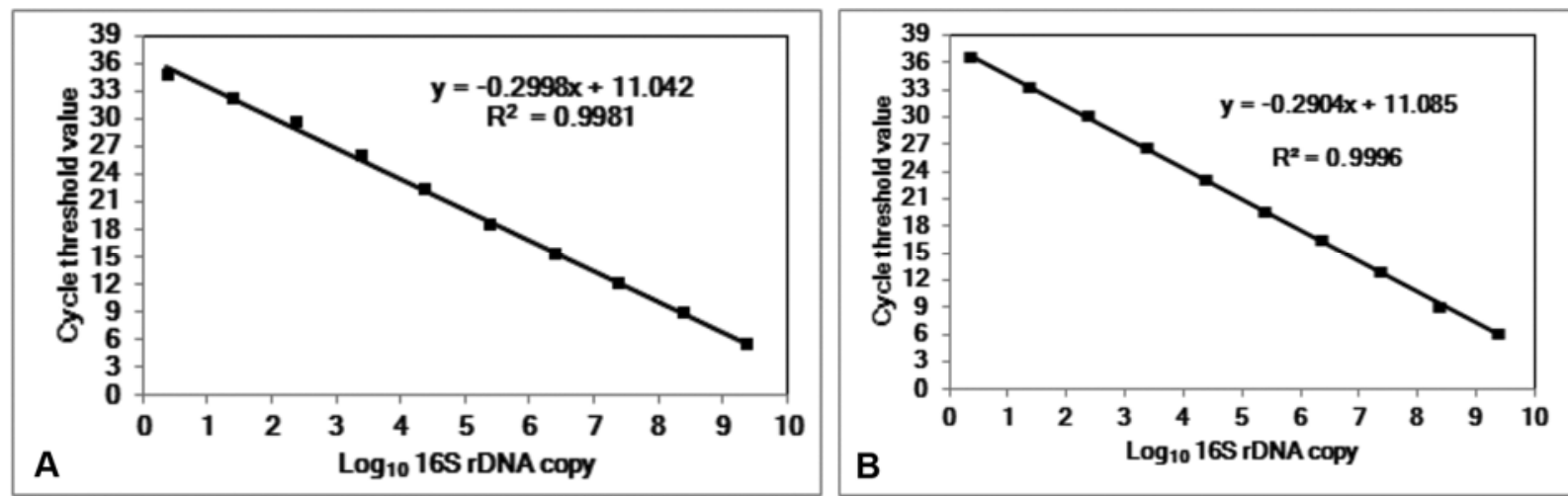

Fig. 3. Standard curves, correlation equations, and correlation coefficients for 'Candidatus Liberibacter asiaticus' quantification in A, plants and B, Diaphorina citri. 
lower titers were detected on all plants exposed to 24 to $38^{\circ} \mathrm{C}$. Average titers varied between 5.12 and $6.28 \log$ ' $\mathrm{Ca}$. L. asiaticus' genomes per gram of tissue (log ' $\mathrm{Ca}$. L. asiaticus') (general average 5.91) on plants maintained inside the greenhouse and between 3.18 and $5.82 \log$ 'Ca. L. asiaticus' (general average 4.93) on plants maintained in the growth chamber.

During periodic observations and at the end of the AAP of $48 \mathrm{~h}$, most confined insects were probing or feeding on the new flush growth. Average rates of ' $\mathrm{Ca}$. L. asiaticus' acquisition by the psyllids were significantly lower in the group of insects that fed on plants exposed to the 24 to $38^{\circ} \mathrm{C}$ regime in the growth chamber. This effect was observed on plants regardless of the stage of infection $(60,120$, or $180 \mathrm{dpi})$ and in nearly all incubation periods. ' $C a$. L. asiaticus' was detected in $53.4,88.1$, and $78.1 \%$ of the insects that fed on the 60-, 120-, or 180-dpi plants, respectively, maintained in the greenhouse, and in $25.0,35.7$, and $26.7 \%$ of the insects that fed on the 60-, 120-, or 180-dpi plants, respectively, maintained in the growth chamber. Average ' $\mathrm{Ca}$. L. asiaticus' titers in the qPCR+ samples were also generally lower in the group of insects that fed on plants maintained in the growth chamber, differing statistically in two of the six incubation periods that allowed comparisons of means.

To determine whether the growth chamber temperature regime ( 24 to $38^{\circ} \mathrm{C}$ ) affected ' $\mathrm{Ca}$. L. asiaticus' viability in plant tissues, attempts were made to graft transmit the bacterium from the experimental to healthy plants, just after flushes and insects were removed for qPCR analysis. The budsticks used for inoculation were removed from the stem of the experimental plants just below the site where new growth flushes had developed. The experimental and inoculated plants were maintained inside the greenhouse for 1 year, when they were assessed for HLB symptoms and by qPCR. HLB and mineral-deficiency symptoms appeared in 68.4 and $80.0 \%$, and ' $\mathrm{Ca}$. L. asiaticus' was detected in 93.0 and $96.4 \%$ of all combined experimental plants, respectively, from growth chamber and greenhouse, which showed similar titers $(5.39 \pm 0.18$ and $4.70 \pm 0.27 \mathrm{log}$ genomes per gram of tissue). Analyses of infection rates and symptom development on the plants graft-inoculated with budsticks from the experimental plants were biased due to a high rate of budstick mortality. Six weeks after grafting, $86.6 \%$ of budsticks that were removed from the plants maintained in the growth chamber and $67.9 \%$ of budsticks that were removed from the plants maintained in in the greenhouse were dead. Of 25 graftinoculated plants with viable budsticks from the growth chamber, $48.0 \%$ exhibited HLB symptoms and $60.0 \%$ were ' $\mathrm{Ca}$. L. asiaticus' positive, with an average titer of $5.35 \pm 0.18 \mathrm{log}$ genomes per gram of tissue. Of the 50 graft-inoculated plants with viable budsticks from the greenhouse, $92.0 \%$ exhibited HLB symptoms and $100.0 \%$ were ' $C a$. L. asiaticus' positive, with an average titer of $4.97 \pm 0.85$ $\log$ genomes per gram of tissue.

Second experiment. The second experiment involved three daily temperature regimes in growth chambers. Prior to pruning and use in the experiment, all plants exhibited strong HLB and mineral-deficiency symptoms, similar to those described for the plants $180 \mathrm{dpi}$ in the first experiment. To assess ' $\mathrm{Ca}$. L. asiaticus' titers and acquisition rates after shorter periods of exposures (every 3 days), the plants were transferred to the chambers after new flush growth had developed for 3 weeks after pruning. The flushes continued to grow, though at a slower rate at the 12 to $24^{\circ} \mathrm{C}$ regime than at higher temperatures.

Comparisons of exposure times on the frequency of infected plants within each temperature regime showed variable results (Table 2). Impacts of the 12 to 24 or 18 to $30^{\circ} \mathrm{C}$ regime were barely detectable: 96 and $100 \%$ of the plants, respectively, tested positive for the presence of ' $\mathrm{Ca}$. L. asiaticus'. However, for the 24 to $38^{\circ} \mathrm{C}$ regime, as the interval over which the plants were held at this temperature increased, the frequency of infection declined gradually from $5 / 5$ after 3 days to $0 / 5$ after 20 days, before increasing to $3 / 5$ after 30 days.

Intervals over which infected plants were held under each temperature regime did not have significant effects on ' $\mathrm{Ca}$. L $\mathrm{L}$. asiaticus' titers, with one exception: ' $C a$. L. asiaticus' titers in plants held at 12 to $24^{\circ} \mathrm{C}$ for 30 days were $6.88 \pm 0.05$ in contrast to 4.64 \pm 0.73 to $5.89 \pm 0.53 \log$ ' $\mathrm{Ca}$. L. asiaticus' for plants held for 3 to 27 days. However, comparisons made between daily temperature regimes showed a consistent effect of the 24 to $38^{\circ} \mathrm{C}$ regime on ' $C a$. L. asiaticus' titers. The titers in plants maintained under this regime were significantly lower than those detected on plants maintained under the other two regimes of lower temperatures after all time periods of exposures.

The rates of ' $\mathrm{Ca}$. L. asiaticus' acquisition by $\mathrm{D}$. citri adults that fed on plants maintained under different temperature regimes also varied within and between regimes. The overall frequencies and

Table 1. Frequencies and titers of 'Candidatus Liberibacter asiaticus' genomes in new growth flushes of graft-inoculated citrus plants exposed for 15 , 30 , and 60 days at two daily temperature regimes, and frequencies of acquisition and titers of ' $\mathrm{Ca}$. L. asiaticus' in adult Diaphorina citri caged for 48 -h on the same plants after the different exposure periods ${ }^{\mathrm{u}}$

\begin{tabular}{|c|c|c|c|c|c|c|c|c|}
\hline \multirow[b]{3}{*}{ DAI, exposure ${ }^{v}$} & \multicolumn{4}{|c|}{ Frequencies and titers of ' $\mathrm{Ca}$. L. asiaticus' in plants } & \multicolumn{4}{|c|}{ Frequencies of acquisition and titers of ' $\mathrm{Ca}$. $\mathrm{L}$. asiaticus' in $\mathrm{D}$. citri } \\
\hline & \multicolumn{2}{|c|}{14.6 to $28^{\circ} \mathrm{C}$ (Greenhouse) } & \multicolumn{2}{|c|}{24 to $38^{\circ} \mathrm{C}$ (Growth chamber) } & \multicolumn{2}{|c|}{14.6 to $28^{\circ} \mathrm{C}$ (Greenhouse) } & \multicolumn{2}{|c|}{24 to $38^{\circ} \mathrm{C}$ (Growth chamber) } \\
\hline & qPCR+/total ${ }^{w}$ & $\log \pm \operatorname{SE}^{x}$ & qPCR+/total ${ }^{w}$ & $\log \pm \operatorname{SE}^{x}$ & qPCR+/total ${ }^{y}$ & $\log \pm \mathbf{S E}^{\mathbf{Z}}$ & qPCR+/total ${ }^{y}$ & $\log \pm \mathbf{S E}^{\mathrm{Z}}$ \\
\hline \multicolumn{9}{|l|}{60} \\
\hline 15 & $7 / 7$ & $5.12 \pm 0.29 \mathrm{a}$ & $0 / 7$ & 0 & $8 / 23(34.8)$ & $3.15 \pm 0.21 \mathrm{a}$ & $0 / 21(0)$ & 0 \\
\hline 30 & $7 / 7$ & $5.40 \pm 0.27 \mathrm{aA}$ & $2 / 7$ & $3.18 \pm 0.95 \mathrm{aB}$ & $12 / 14(85.7)$ & $3.34 \pm 0.25 \mathrm{aA}$ & $2 / 14(14.2)$ & $2.10 \pm 0.42 \mathrm{aA}$ \\
\hline 60 & $5 / 7$ & $5.82 \pm 0.50 \mathrm{aA}$ & $1 / 7$ & $5.11 \mathrm{aA}$ & $11 / 21(52.4)$ & $3.36 \pm 0.45 \mathrm{aA}$ & $12 / 21(57.1)$ & $2.15 \pm 0.20 \mathrm{aB}$ \\
\hline Total/average & $19 / 21(90.5)$ & $5.41 \pm 0.19$ & $3 / 21(14.3)$ & $3.82 \pm 0.84$ & $31 / 58(53.4)$ & $3.30 \pm 0.19$ & $14 / 56(25.0)$ & $2.14 \pm 0.17$ \\
\hline \multicolumn{9}{|l|}{120} \\
\hline 15 & $6 / 7$ & $5.69 \pm 0.06 \mathrm{aA}$ & $7 / 7$ & $5.43 \pm 0.14 \mathrm{aA}$ & $20 / 20(100)$ & $2.85 \pm 0.14 \mathrm{aA}$ & $9 / 18(50.0)$ & $2.18 \pm 0.25 \mathrm{aA}$ \\
\hline 30 & $7 / 7$ & $6.28 \pm 0.23 \mathrm{aA}$ & $7 / 7$ & $5.36 \pm 0.29 \mathrm{aA}$ & $18 / 18(100)$ & $3.18 \pm 0.21 \mathrm{aA}$ & $8 / 17(47.1)$ & $2.11 \pm 0.10 \mathrm{aB}$ \\
\hline 60 & $7 / 7$ & $6.01 \pm 0.05 \mathrm{aA}$ & $6 / 7$ & $5.27 \pm 0.18 \mathrm{aA}$ & $14 / 21(66.7)$ & $2.20 \pm 0.08 \mathrm{aA}$ & $3 / 21(14.3)$ & $1.97 \pm 0.10 \mathrm{aA}$ \\
\hline Total/average & $20 / 21(95.2)$ & $6.01 \pm 0.09$ & $20 / 21(95.2)$ & $5.36 \pm 0.12$ & $52 / 59(88.1)$ & $2.79 \pm 0.11$ & $20 / 56(35.7)$ & $2.12 \pm 0.12$ \\
\hline \multicolumn{9}{|l|}{180} \\
\hline 15 & $6 / 7$ & $6.18 \pm 0.05 \mathrm{aA}$ & $7 / 7$ & $5.82 \pm 0.03 \mathrm{aA}$ & $18 / 20(85.7)$ & $2.75 \pm 0.13 \mathrm{aA}$ & $12 / 21(57.1)$ & $1.98 \pm 0.07 \mathrm{aA}$ \\
\hline 30 & $2 / 3$ & $5.88 \pm 0.0 \mathrm{aA}$ & $4 / 4$ & $4.81 \pm 0.14 \mathrm{aA}$ & $6 / 9(66.7)$ & $2.69 \pm 0.30 \mathrm{a}$ & $0 / 11(0)$ & 0 \\
\hline 60 & $2 / 3$ & $6.01 \pm 0.11 \mathrm{aA}$ & $3 / 4$ & $4.96 \pm 0.32 \mathrm{aA}$ & $8 / 12(66.7)$ & $3.27 \pm 0.09 \mathrm{a}$ & $0 / 13(0)$ & 0 \\
\hline Total/average & $10 / 13(76.9)$ & $6.09 \pm 0.05$ & $14 / 15(93.3)$ & $5.35 \pm 0.15$ & $32 / 41(78.1)$ & $2.87 \pm 0.10$ & $12 / 45(26.7)$ & $1.98 \pm 0.07$ \\
\hline Totals/averages & $49 / 55(89.1)$ & $5.91 \pm 0.16$ & $37 / 57(64.9)$ & $4.93 \pm 0.32$ & $115 / 158(72.8)$ & $3.45 \pm 0.22$ & $46 / 157$ (29.3) & $3.06 \pm 0.12$ \\
\hline
\end{tabular}

\footnotetext{
u Means were calculated only for the quantitative polymerase chain reaction-positive (qPCR+) samples and the values followed by different letters within the columns (small letters) or between columns (capital letters) are significantly different $(P<0.05)$.

${ }^{\mathrm{v}} \mathrm{DAI}=$ days after inoculation and exposure period (days).

${ }^{\mathrm{w}}$ Number of plants with average quantification cycle $(\mathrm{Cq})$ values $\leq 34.00$ over the total plants and percentage.

${ }^{\mathrm{x}} \log _{10}$ of ' $\mathrm{Ca}$. L. asiaticus' genomes per gram of tissue estimated based on the equation shown in Figure $3 \mathrm{~A}$, plus or minus standard error (SE).

y Total lots of five adult $D$. citri with average Cq values $\leq 34.00$ over the total lot number.

${ }^{\mathrm{z}} \log _{10}$ of 'Ca. L. asiaticus' genomes per lot of insects, estimated based on the equation shown in Figure 3B, plus or minus SE.
} 
percentages of 'Ca. L. asiaticus'-carrying D. citri was 26/50 (52\%) of adults from plants maintained at 12 to $24^{\circ} \mathrm{C}, 14 / 50(28.0 \%)$ of adults from plants maintained at 18 at $30^{\circ} \mathrm{C}$, and $1 / 50(2.0 \%)$ of adults from plants maintained at 24 to $38^{\circ} \mathrm{C}$. The ' $\mathrm{Ca}$. L. asiaticus' titers detected in the psyllid adults were generally lower than those detected in adults in the first experiment but did not differ significantly among intervals the plants were exposed to the temperature regimes or among the temperature regimes. Within temperature regimes, statistical variations were detected only in the group of adults that fed on plants maintained at 12 to $24^{\circ} \mathrm{C}$.

The effect of the 24 to $38^{\circ} \mathrm{C}$ regime on ' $\mathrm{Ca}$. L. asiaticus' multiplication and acquisition was further tested on an individual 5year-old plant and on a group of 251.5 -year-old graft-inoculated, fully symptomatic plants. On the individual plant, all growth flushes were ' $\mathrm{Ca}$. L. asiaticus' positive, with average ' $\mathrm{Ca}$. L. asiaticus' titers of 5.91, 5.25, 5.05, 5.58, 5.67, and 4.94 genomes per gram of leaf tissue after $0,1,3,5,7$, and 9 days of incubation, respectively (Table 3). All lots of insects that fed on plants incubated at the first three incubation periods carried ' $C a$. L. asiaticus' whereas 70, 60, and $75 \%$ of the lots of insects that fed on plants after 5, 7, and 9 days of incubation, respectively, were ' $\mathrm{Ca}$. L. asiaticus' positive. Higher titers were detected in the insects that fed on plants on the day the plants were transferred to the chamber and after 1 day of incubation than on plants that were incubated for longer periods ( 3 to 9 days).

In the group of 1.5-year-old plants, ' $C a$. L. asiaticus' was detected in all five plants at day 0 and 1 and on three, three, and four of five plants in each time period at days 2, 3, and 4, respectively (Table 3). Average ' $\mathrm{Ca}$. L. asiaticus' titers on the new growth flushes were 4.04, 4.69, 4.70, 5.24, and 3.54 genomes per gram of leaf tissue after $0,1,2,3$, and 4 days of incubation, respectively. Acquisition rates on the individual insects that fed on the incubated plants were $68 \%$ for the first three incubation periods $(0,1$, and 2 days) and 52.0 and $32.0 \%$ after 3 and 4 days. ' $\mathrm{Ca}$. L. asiaticus' titers in the individual insects also varied, with averages of 3.04, 2.06, 2.98, 2.54, and 2.23 ' $\mathrm{Ca}$. L. asiaticus' genomes per insect at days $0,1,2,3$, and 4 , respectively.

\section{Discussion}

Monitoring ' $\mathrm{Ca}$. L. asiaticus' infection in plants and the presence of ' $\mathrm{Ca}$. L. asiaticus' in the psyllid vector by real-time PCR has led to new understanding of HLB host-pathogen-vector relationships. For example, it was demonstrated that ' $C a$. L. asiaticus' multiplies more efficiently and tolerates higher temperatures than ' $\mathrm{Ca}$. L. americanus' in sweet orange $(12,14)$, and ' $\mathrm{Ca}$. L. asiaticus' becomes unevenly distributed in plant tissues $(11,21)$. Also, in mature symptomatic leaves, close to one-third of the ' $\mathrm{Ca}$. L. asiaticus' cells may be dead (24). 'Ca. L. asiaticus' is more efficiently acquired by nymphs of $D$. citri from third to fifth instars than by adults but most adults will carry the pathogen after an AAP of just $24 \mathrm{~h}$ on infected plants (9).

This study was conducted to gain more knowledge about the relative sensitivity of ' $\mathrm{Ca}$. L. asiaticus' to high air temperatures and was conceived based on the results of previous work showing a significant decrease in ' $\mathrm{Ca}$. L. asiaticus' titers in mature leaves that developed in a growth chamber maintained at 24 to $38^{\circ} \mathrm{C}$ (14). In contrast to the previous work, this study focused on ' $\mathrm{Ca}$. L. asiaticus' titers on immature growth flushes, tissues on which $D$. citri prefers to feed. Comparisons of means of $\log _{10}$ ' $\mathrm{Ca}$. L. asiaticus' titers, based on the number of ' $\mathrm{Ca}$. L. asiaticus' genomes per gram of new flush tissue, or per individual or groups of three or five adults of $D$. citri, were made only with qPCR-positive samples. ' $C a$. L. asiaticus' titer reductions in plant tissues were variable. Although average values were lower in most heat-exposed plants, the differences were statistically significant only for the plants at the early stage of symptom development (60 dpi) in the first experiment and for all plants exhibiting severe stage symptoms in the second experiment. The reasons for this variation are unknown but could be related to differences in the physiological status of the bacteria living inside the plants, which may not be related to the severity of the symptoms expressed by the plant. These potential occurrences of nonviable ' $\mathrm{Ca}$. L. asiaticus' would not be identified by qPCR. Graft transmission using budsticks from plants exposed and not exposed to high temperatures were evaluated in the first experiment to determine the viability of ' $\mathrm{Ca}$. L. asiaticus' in plant tissues. Although high budstick mortality permitted only tentative analysis of this matter, the lower rates of transmission from plants exposed to high temperatures indicates that the heat treatment reduced the viability of the bacterium present in the budstick. However, severe HLB and associated mineral-deficiency symptoms developed in most of the experimental plants that served as sources of budsticks for graft inoculations. ' $C a$. L. asiaticus' could be surviving in the roots because temperatures of the substrate in the pots in which the plants grew were 6 to $8^{\circ} \mathrm{C}$ lower than in the air. From the roots, the bacterium might have invaded the new branches and leaves that developed on the upper portions of the plants after heat treatment ceased. Similar phenomena would explain the ineffectiveness of heat treatments on affected plants in the field, where much higher temperatures have been tested (unpublished data).

Table 2. Frequencies and titers of 'Candidatus Liberibacter asiaticus' genomes in new growth flushes of infected citrus plants exposed for various time intervals at three daily temperature regimes, and frequencies of acquisition and titers of ' $\mathrm{Ca}$. L. asiaticus' in adult Diaphorina citri caged for 48 -h on the same plants after the different exposure periods ${ }^{\mathrm{u}}$

\begin{tabular}{|c|c|c|c|c|c|c|c|c|c|c|c|c|}
\hline \multirow[b]{3}{*}{ Days $v$} & \multicolumn{6}{|c|}{ Frequencies and titers of ' $\mathrm{Ca}$. L. asiaticus' in plants } & \multicolumn{6}{|c|}{ Frequencies of acquisition and titers of ' $\mathrm{Ca}$. L. asiaticus' in $\mathrm{D}$. citri } \\
\hline & \multicolumn{2}{|c|}{12 to $24^{\circ} \mathrm{C}$} & \multicolumn{2}{|c|}{18 to $30^{\circ} \mathrm{C}$} & \multicolumn{2}{|c|}{24 to $38^{\circ} \mathrm{C}$} & \multicolumn{2}{|c|}{12 to $24^{\circ} \mathrm{C}$} & \multicolumn{2}{|c|}{18 to $30^{\circ} \mathrm{C}$} & \multicolumn{2}{|c|}{24 to $38^{\circ} \mathrm{C}$} \\
\hline & $\mathbf{P C R}+/$ tot $^{\mathrm{w}}$ & $\log \pm \mathrm{SE}^{\mathrm{X}}$ & PCR+/tot ${ }^{w}$ & $\log \pm S E^{X}$ & PCR+/tot ${ }^{w}$ & $\log \pm S E^{X}$ & PCR+/tot ${ }^{y}$ & $\log \pm \mathrm{SE}^{\mathrm{Z}}$ & PCR+/tot ${ }^{y}$ & $\log \pm S E^{\mathrm{Z}}$ & PCR+/tot $\mathbf{y}^{\mathbf{y}}$ & $\log \pm \mathbf{S E}^{\mathrm{Z}}$ \\
\hline 3 & $5 / 5$ & $4.64 \pm 0.73 \mathrm{bA}$ & $5 / 5$ & $5.51 \pm 0.53 \mathrm{aA}$ & $5 / 5$ & $3.90 \pm 0.33 \mathrm{aB}$ & $4 / 5$ & $1.91 \pm 0.08 \mathrm{bA}$ & $3 / 5$ & $1.93 \pm 0.10 \mathrm{aA}$ & $0 / 5$ & 0 \\
\hline 6 & $5 / 5$ & $6.39 \pm 0.15 \mathrm{bA}$ & $5 / 5$ & $6.42 \pm 0.13 \mathrm{aA}$ & $4 / 5$ & $3.78 \pm 0.43 \mathrm{aB}$ & $3 / 5$ & $1.82 \pm 0.05 \mathrm{bA}$ & $3 / 5$ & $2.26 \pm 0.08 \mathrm{aA}$ & $1 / 5$ & $2.45 \mathrm{~A}$ \\
\hline 9 & $5 / 5$ & $5.67 \pm 0.59 \mathrm{bA}$ & $5 / 5$ & $6.13 \pm 0.26 \mathrm{aA}$ & $4 / 5$ & $2.80 \pm 0.28 \mathrm{aB}$ & $1 / 5$ & $1.90 \mathrm{~b}$ & $0 / 5$ & 0 & $0 / 5$ & 0 \\
\hline 12 & $4 / 5$ & $6.29 \pm 0.17 \mathrm{bA}$ & $5 / 5$ & $6.20 \pm 0.09 \mathrm{aA}$ & $4 / 5$ & $4.09 \pm 0.70 \mathrm{aB}$ & $5 / 5$ & $2.67 \pm 0.07 \mathrm{a} \mathrm{A}$ & $4 / 5$ & $2.16 \pm 0.13 \mathrm{aA}$ & $0 / 5$ & 0 \\
\hline 15 & $5 / 5$ & $6.67 \pm 0.05 \mathrm{bA}$ & $5 / 5$ & $5.53 \pm 0.77 \mathrm{aA}$ & $4 / 5$ & $3.24 \pm 0.31 \mathrm{aB}$ & $3 / 5$ & $1.98 \pm 0.12 \mathrm{~b}$ & $0 / 5$ & 0 & $0 / 5$ & 0 \\
\hline 18 & $5 / 5$ & $6.28 \pm 0.29 \mathrm{bA}$ & $5 / 5$ & $6.54 \pm 0.11 \mathrm{aA}$ & $5 / 5$ & $3.11 \pm 0.16 \mathrm{aB}$ & $4 / 5$ & $2.29 \pm 0.19 \mathrm{ab}$ & $2 / 5$ & $2.09 \pm 0.06 \mathrm{a}$ & $0 / 5$ & 0 \\
\hline 21 & $5 / 5$ & $5.94 \pm 0.17 \mathrm{bA}$ & $5 / 5$ & $6.11 \pm 0.25 \mathrm{aA}$ & $2 / 5$ & $2.67 \pm 0.06 \mathrm{aB}$ & $0 / 5$ & 0 & $0 / 5$ & 0 & $0 / 5$ & 0 \\
\hline 24 & $4 / 5$ & $6.28 \pm 0.13 \mathrm{bA}$ & $5 / 5$ & $6.39 \pm 0.16 \mathrm{aA}$ & $1 / 5$ & $2.43 \mathrm{aB}$ & $3 / 5$ & $2.15 \pm 0.23 \mathrm{abA}$ & $1 / 5$ & $1.98 \mathrm{aA}$ & $0 / 5$ & 0 \\
\hline 27 & $5 / 5$ & $5.89 \pm 0.53 \mathrm{bA}$ & $5 / 5$ & $6.33 \pm 0.09 \mathrm{aA}$ & $0 / 5$ & 0 & $0 / 5$ & 0 & $0 / 5$ & 0 & $0 / 5$ & 0 \\
\hline 30 & $5 / 5$ & $6.88 \pm 0.05 \mathrm{aA}$ & $5 / 5$ & $6.54 \pm 0.16 \mathrm{aA}$ & $3 / 5$ & $2.63 \pm 0.04 \mathrm{aB}$ & $3 / 5$ & $2.36 \pm 0.15 \mathrm{bA}$ & $1 / 5$ & $1.83 \mathrm{aA}$ & $0 / 5$ & 0 \\
\hline Tot/avg & $48 / 50$ & $6.08 \pm 0.14$ & $50 / 50$ & $6.17 \pm 0.26$ & $32 / 50$ & $3.18 \pm 0.29$ & $26 / 50$ & $2.19 \pm 0.07$ & $14 / 50$ & $2.09 \pm 0.06$ & $1 / 50$ & 2.45 \\
\hline Percent & $96 \%$ & $\ldots$ & $100 \%$ & $\ldots$ & $64.0 \%$ & $\ldots$ & $52.0 \%$ & $\ldots$ & $28.0 \%$ & $\ldots$ & $2.0 \%$ & $\ldots$ \\
\hline
\end{tabular}

u Means were calculated only for the quantitative polymerase chain reaction-positive (PCR+) samples and the values followed by different letters within the columns (small letters) or between columns (capital letters) are significantly different $(P<0.05)$.

${ }^{v}$ Exposure period. Tot/avg $=$ totals/averages.

${ }^{\mathrm{w}}$ Number of plants with average quantification cycle $(\mathrm{Cq})$ values $\leq 34.00$ over the total (tot) plants and percentage.

${ }^{\mathrm{x}} \log _{10}$ of 'Ca. L. asiaticus' genomes per leaf sample, estimated based on the equation shown in Figure 3A, plus or minus standard error (SE).

y Total lots of five adult $D$. citri with average Cq values $\leq 34.00$ over the total (tot) lot number.

${ }^{\mathrm{z}} \log _{10}$ of ' $\mathrm{Ca}$. L. asiaticus' genomes per lot of insects, estimated based on the equation shown in Figure 3B, plus or minus SE. 
To gain a better understanding of the HLB spread to and within distinct geographic regions, the potential of the new flushes as source of inoculum also was evaluated through assessments of the frequency of adult $D$. citri in acquiring the bacterium when feeding on plants exposed to different environments. In all groups of plants exposed to the 24 to $38^{\circ} \mathrm{C}$ regime, a decline in acquisition rates by adult $D$. citri, starting after 3 to 5 days of exposure, was observed. The declines in acquisition rates varied among experiments and, in many cases, were not followed by a decline in ' $\mathrm{Ca}$. L. asiaticus' titers in the heat-exposed plants. Statistically similar titers in plants resulted in variable acquisition rates by the insects. Correlation analysis confirmed a lack of relationship between these variables (results not shown). This could be related to variation in the proportions of dead to live ' $\mathrm{Ca}$. L. asiaticus' cells in the sampled tissues, as mentioned above, which could be higher in the plants exposed to the highest temperature regime. The presence of dead ' $\mathrm{Ca}$. L. asiaticus' cells in symptomatic plant tissues has already been shown (24). In addition, although $D$. citri survival rates after the 48 -h AAP in plants exposed or not exposed to high temperatures were similar, a possibility exists that the high temperatures also affected plant tissues and, consequently, insect feeding behavior.

The decrease in ' $\mathrm{Ca}$. L. asiaticus' acquisition rates by the adult psyllids that fed on plants exposed to the 24 to $38^{\circ} \mathrm{C}$ environment was not consistently related to declines in ' $\mathrm{Ca}$. L. asiaticus' titers in adults. The effectiveness of the insect feeding on the distinct groups of plants in inoculating the bacterium to healthy citrus was not investigated in this work. Because the rate of effective ' $\mathrm{Ca}$. L. asiaticus' transmission when the bacterium is acquired by adults is already low (9), it would be interesting to assess ' $C a$. L. asiaticus' acquisition rates by individual $D$. citri nymphs.

In this study, groups of three and five $D$. citri adults and individual insects were used to determine ' $\mathrm{Ca}$. L. asiaticus' acquisition rates during a 48-h AAP. The observed average acquisition percentages from plants not exposed to high temperatures $(60.1 \%)$ were lower than those described by Inoue et al. (9) using individual insects $(88.0 \%)$ for a 24 -h AAP but higher than those detected in the study by Pelz-Stelinsky (19), in which no adults in groups of 50 insects acquired ' $C a$. L. asiaticus', even after a 1-week AAP. Variation in the local populations of D. citri, experimental procedures, infection status of the plants used, leaf maturity, and, as demonstrated in this work, the environmental conditions to which the plants were exposed may be responsible for the differences.

The partial tolerance of ' $\mathrm{Ca}$. L. asiaticus' to high air temperatures (14) was confirmed in this work and was shown to have im- portant consequences for the acquisition of the bacterium by the insect vector. The partial tolerance of ' $\mathrm{Ca}$. L. asiaticus' to high temperatures may also explain the seasonal variation of this bacterium observed in citrus branches and D. citri in Florida citrus groves (18). Potential interference of high temperatures on ' $\mathrm{Ca}$. L. asiaticus' multiplication inside the bodies of the insect vector and on the establishment of ' $\mathrm{Ca}$. L. asiaticus' infection in plant tissues are aspects that are under investigation in our laboratory.

Although environmental factors other than ambient temperatures might ultimately affect HLB epidemics, the data obtained in this research strongly suggest that seasonal variation in daily air temperatures among regional citrus-growing districts influence irregular spatial patterns of disease spread observed over time in the state of São Paulo. It is envisioned that, in other Brazilian states with similar variation in climatic conditions, and in California and Texas in the United States, where HLB has been recently reported, a pattern of spatial disease progress similar to the one in São Paulo should be expected. It is also possible that some citrus areas, such as those in irrigated desert regions, may not be as severely affected by the disease as citrus areas with cooler and more moderate climates. Such impacts would be greater if moisture stress, particularly wilting, increased the frequency of high leaf temperatures detrimental to the pathogen and survival of $D$. citri. Leaf titers of the pathogen in tropical and subtropical regions may also be influenced by situations where high relative humidities and ambient temperatures limit evaporative cooling of the leaves.

\section{Acknowledgments}

This work was financed by Conselho Nacional de Desenvolvimento Científico e Tecnológico (CNPq), grant number 578310/2008-2. We thank L. W. Timmer, Professor Emeritus, University of Florida, Lake Alfred, for useful suggestions during manuscript preparation; N. A. Wulff for adjustments in the qPCR protocol; and M. A. Santos, Fundecitrus, for help with figure preparation.

\section{Literature Cited}

1. Belasque, J., Jr., Barbosa, J. C., Massari, C. A., and Ayres, A. J. 2010. Incidência e distribuição do huanglongbing no estado de São Paulo, Brasil Citrus Res. Technol. 31:1-9.

2. Bové, J. M. 2006. Huanglongbing: a destructive, newly-emerging, centuryold disease of citrus. J. Plant Pathol. 88:7-37.

3. Capoor, S. P., Rao, D. G., and Viswanath, S. M. 1967. Diaphorina citri Kuwayama, a vector of the greening disease of citrus in India. Ind. J. Agric. Sci. 37:572-576.

4. Colleta-Filho, H. D., Targon, M. L. P. N., Takita, M. A., De Negri, J. D., Amaral, A. M., Müller, G. W., Pompeu Júnior, J., Carvalho, S. A., and Machado, M. A. 2004. Detecção do agente causal do greening do citros (Candidatus Liberibacter asiaticus) no estado de São Paulo. Summa Phytopathol 30:510.

Table 3. Frequencies and titers of 'Candidatus Liberibacter asiaticus' genomes in new growth flushes of an individual 5-year-old potted tree or in a group of potted plants affected by huanglongbing after exposure at the 24 to $38^{\circ} \mathrm{C}$ daily temperature regime for different time periods, and frequency of acquisition and titers of ' $\mathrm{Ca}$. L. asiaticus' in adult Diaphorina citri caged for $48 \mathrm{~h}$ on the same plants after the different exposure periods ${ }^{\mathrm{v}}$

\begin{tabular}{|c|c|c|c|c|}
\hline \multirow[b]{2}{*}{ Exposure period (days) } & \multicolumn{2}{|c|}{$\begin{array}{l}\text { Frequency and titer of ' } \mathrm{Ca} \text {. } \mathrm{L} \text {. asiaticus' } \\
\text { in new flush growth }\end{array}$} & \multicolumn{2}{|c|}{$\begin{array}{c}\text { Frequency and titer of 'C } \mathrm{Ca} \text {. L. asiaticus' } \\
\text { in D. citri }\end{array}$} \\
\hline & qPCR+/total ${ }^{w}$ & $\log \pm \operatorname{SE}^{\mathrm{x}}$ & qPCR+/total ${ }^{y}$ & $\log \pm \mathrm{SE}^{\mathrm{z}}$ \\
\hline \multicolumn{5}{|l|}{ 5-year-old tree } \\
\hline 0 & $10 / 10$ & $5.91 \pm 0.15$ & $9 / 9(100)$ & $4.40 \pm 0.81$ \\
\hline 1 & $10 / 10$ & $5.25 \pm 0.06$ & $10 / 10(100)$ & $3.43 \pm 0.08$ \\
\hline 3 & $10 / 10$ & $5.05 \pm 0.10$ & $10 / 10(100)$ & $2.48 \pm 0.07$ \\
\hline 5 & $10 / 10$ & $5.58 \pm 0.14$ & $7 / 10(70)$ & $2,21 \pm 0.26$ \\
\hline 7 & $9 / 9$ & $5.67 \pm 0.10$ & $6 / 10(60)$ & $2.01 \pm 0.09$ \\
\hline 9 & $8 / 8$ & $4.94 \pm 0.11$ & $6 / 8(75)$ & $2.62 \pm 0.30$ \\
\hline \multicolumn{5}{|l|}{1.5 -year-old plants } \\
\hline 0 & $5 / 5$ & $4.04 \pm 0.55$ & $17 / 25(68.0)$ & $3.04 \pm 0.16$ \\
\hline 1 & $5 / 5$ & $4.69 \pm 0.07$ & $17 / 25(68.0)$ & $2.06 \pm 0.06$ \\
\hline 2 & $3 / 5$ & $4.70 \pm 0.83$ & $17 / 25(68.0)$ & $2.98 \pm 0.21$ \\
\hline 3 & $3 / 5$ & $5.24 \pm 0.12$ & $13 / 25(52.0)$ & $2,54 \pm 0,10$ \\
\hline 4 & $4 / 5$ & $3.54 \pm 0.53$ & $8 / 25(32.0)$ & $2.23 \pm 0.11$ \\
\hline
\end{tabular}

${ }^{\mathrm{v}}$ Means were calculated only for the quantitative polymerase chain reaction-positive (qPCR+) samples.

${ }^{w}$ Number of new flushes with average quantification cycle $(\mathrm{Cq})$ values $\leq 34.00$ over the total number of flushes.

${ }^{\mathrm{x}} \log _{10}$ of ' $\mathrm{Ca}$. L. asiaticus' genomes per gram of tissue, estimated based on the equation shown in Figure 3A, plus or minus standard error (SE).

${ }^{\mathrm{y}}$ Total lots of three adult (single 5-year-old tree) or individual (1.5-year-old plants) D. citri with average Cq values $\leq 34.00$ over the total lot or individuals.

${ }^{\mathrm{z}} \log _{10}$ of 'Ca. L. asiaticus' genomes per lot of insects or individuals, estimated based on the equation shown in Figure 3B, plus or minus SE. 
5. da Graça, J. V. 1991. Citrus greening disease. Annu. Rev. Phytopathol. 29:109-136.

6. Dhanasekaran, S., Doherty, T. M., and Kenneth, J. 2010. Comparison of different standards for real-time PCR-based absolute quantification. J. Immunol. Methods 354:34-39.

7. Gottwald, T. R., Graça, J. V., and Bassanezi, R. B. 2007. Citrus huanglongbing: the pathogen and its impact. Plant Health Progress. Online publication. doi:10.1094/PHP-2007-0906-01-RV

8. Hocquellet, A., Toorawa, P., Bové, J. M., and Garnier, M. 1999. Detection and identification of the two Candidatus Liberibacter species associated with citrus huanglongbing by PCR amplification of ribosomal protein genes of the beta operon. Mol. Cell. Probes 13:373-379.

9. Inoue, H., Ohnishi, J., Ito, T., Tomimura, K., Miyata, S., Iwanami, T., Ashihara, W. 2009. Enhanced proliferation and efficient transmission of Candidatus Liberibacter asiaticus by adult Diaphorina citri after acquisition feeding in the nymphal stage. Ann. Appl. Biol. 155:29-36.

10. Kim, J., and Wang, N. 2009. Characterization of copy numbers of $16 \mathrm{~S}$ sDNA and 16S rRNA of Candidatus Liberibacter asiaticus and the implication in detection in planta using quantitative PCR. BCM Res. Notes 2:37. Online publication. doi:10.1186/1756-0500-2-37

11. Li, W., Levy, L., and Hartung, J. S. 2009. Quantitative distribution of 'Candidatus Liberibacter asiaticus' in citrus plants with citrus huanglongbing. Phytopathology 99:139-144.

12. Lopes, S. A., Bertolini, E., Frare, G. F., Martins, E. C., Wulff, N. A., Teixeira, D. C., Fernandes, N. G., and Cambra, M. 2009. Graft transmission efficiencies and multiplication of 'Candidatus Liberibacter americanus' and 'Ca. Liberibacter asiaticus' in citrus plants. Phytopathology 99:301-306.

13. Lopes, S. A., and Frare, G. F. 2008. Graft transmission and cultivar reaction of citrus to 'Candidatus Liberibacter americanus'. Plant Dis. 92:21-24.

14. Lopes, S. A., Frare, G. F., Bertolini, E., Cambra. M., Fernandes, N. G., Ayres, A. J., Marin, D. R., Bové, J. M. 2009. Liberibacters associated with citrus huanglongbing in Brazil: 'Candidatus Liberibacter asiaticus' is heat tolerant, 'Ca. L. americanus' is heat sensitive. Plant Dis. 93:257-262.

15. Lopes, S. A., Frare, G. F., Camargo, L. E. A., Wulff, N. A., Teixeira, D. C., Bassanezi, R. B., Beattie, G. A. C., and Ayres, A. J. 2010. Liberibacters associated with orange jasmine in Brazil: incidence in urban areas and relat- edness to citrus Liberibacters. Plant Pathol. 59:1044-1053.

16. Maschio, F. 2011. Ações adotadas pelo citricultor para manejo do huanglongbing (HLB, greening) no parque citrícola paulista. Tese de mestrado. Araraquara SP Fundo de Defesa da Citricultura, Araraquara, SP, Brazil.

17. Murray, M. G., and Thompson, W. F. 1980. Rapid isolation of high molecular weight plant DNA. Nucleic Acids Res. 8:4321-4325.

18. Parkunan, V., Ebert, T., Wang, N., Rogers, M., and Dewdney, M. 2011. Seasonal variation of Candidatus Liberibacter asiaticus in citrus branches and in vector, Diaphorina citri, in Central Florida sweet orange groves. (Abstr.) Phytopathology 101:S138.

19. Pelz-Stelinski, K. S., Brlansky, R. H., Ebert, T. A., and Rogers, M. E. 2010 Transmission parameters for Candidatus Liberibacter asiaticus by Asian citrus psyllid (Hemiptera: Psyllidae). J. Econ. Entomol. 103:1531-1541.

20. SAS Institute. 2005. SAS Users' Guide. SAS Institute, Cary, NC.

21. Tatineni, S., Sagaram, U. S., Gowda, S., Robertson, C. J., Dawson, W. O., Iwanami, T., and Wang, N. 2008. In planta distribution of 'Candidatus Liberibacter asiaticus' as revealed by polymerase chain reaction (PCR) and real-time PCR. Phytopathology 98:592-599.

22. Teixeira, D. C., Danet, J. L., Eveillard, S., Martins, E. C., Jesus Junior, W. C, Yamamoto, P. T., Lopes, S. A., Bassanezi, R. B., Ayres, A. J., Saillard, C., and Bové, J. M. 2005. Citrus huanglongbing in São Paulo state, Brazil: PCR detection of the 'Candidatus' Liberibacter species associated with the disease. Mol. Cell. Probes 19:173-179.

23. Thao, M. L., Moran, N. A., Abbot, P., Brennan, E. B., Burckhardt, D. H., and Baumann, P. 2000. Cospeciation of psyllids and their primary prokaryotic endosymbionts. Appl. Environ. Microbiol. 66:2898-2905.

24. Trivedi, P., Sagaram, U. S., Kim, J. S., Brlansky, R. H., Rogers, M. E., Stelinski, L. L., Oswalt, C., and Wang, N. 2009. Quantification of viable Candidatus Liberibacter asiaticus in hosts using quantitative PCR with the aid of ethidium monoazide (EMA). J. Plant Pathol. 124:553-563.

25. Yamamoto, P. T., Felippe, M. R., Garbim, L. F., Coelho, J. H. C., Ximenes, N. L., Martins, E. C., Leite, A. P. R., Sousa, M. C., Abrahão, D. P., and Braz, J. D. 2006. Diaphorina citri (Kuwayama) (Hemiptera: Psyllidae): vector of the bacterium Candidatus Liberibacter americanus. Page 96 in: Proc. Huanglongbing-Greening Int. Workshop, Ribeirão Preto, Brazil. 